\title{
MODELOS SENCILLOS DE DEPÓSITO MUESTRAN \\ QUE LA RESERVA FRACCIONARIA \\ NO ES SOSTENIBLE EN EL TIEMPO \\ SALVO APLICACIÓN \\ DE (NUEVA) COACCIÓN
}

\author{
JORGE BUESO MERINO*
}

Fecha de recepción: 5 de octubre de 2016

Fecha de aceptación: 12 de febrero de 2017

\section{I \\ INTRODUCCIÓN}

Ludwig von Mises mostró que existen dos clases de crédito, crédito mercancía (Sachkredit) y crédito circulatorio (Zirkulationskredit), y señaló a este último como el origen de los ciclos de auge y recesión que de modo recidivante azotan nuestras sociedades (Mises 1912: 296-300, 396-404). En nuestros días Huerta de Soto, continuando ${ }^{1}$ dicha línea de trabajo, ha perfilado la distinción radical que existe entre la institución del depósito y las del mutuo o préstamo, y ha mostrado cómo a partir de la confusión o «desdiferenciación» de ambas se vienen a generar los problemas indicados (Huerta de Soto 1998).

Una opinión crítica, sin embargo, apunta hacia otra causa que se aduce como alternativa: el descalce de plazos en el crédito (Selgin y White [1996], ² Barnett y Block [2009], o también Juan Ramón

* Investigador independiente. Máster en Economía de la Escuela Austriaca (URJC). Email: jorgebueso@icav.es

${ }^{1}$ Mediante su muy eficaz triple aproximación teórica, histórica y ética.

2 Autores cuya propuesta de banca libre con reserva fraccionaria ha sido sometida a crítica por Huerta de Soto (1998: 525-550), demostrando que la emisión y circulación 
Rallo y Francisco Capella, según las referencias citadas en las notas 15 y 20).

El propósito del presente trabajo será intentar caracterizar los elementos más simples (Menger 1871: 46-47) que conforman una y otra práctica de manera diferenciada:

a) La reserva fraccionaria en el depósito

b) El descalce de plazos en el crédito.

Para ello utilizaremos modelos sencillos que comprendan las características esenciales de cada actividad, y compararemos los procesos y los efectos que se dan según se vengan a emplear unas pautas u otras en su desarrollo.

\author{
II \\ PROPUESTA DE UN MODELO SENCILLO \\ DE DEPÓSITO QUE AYUDA A VISUALIZAR \\ LOS PROCESOS Y LOS EFECTOS QUE SE DAN \\ AL PRACTICAR LA RESERVA FRACCIONARIA ${ }^{3}$
}

\title{
1. El modelo que se propone: procesos implicados
}

a) Pauta primera: con obligación de custodia

Imaginemos un orfebre en un pueblo más o menos aislado que suele recibir en su taller con bastante regularidad el encargo de un cliente por semana, acompañado por el depósito de un kilogramo del metal correspondiente, que es trabajado conforme a los usos del oficio, y entregado de vuelta a su propietario en la forma desea-

de medios fiduciarios por parte de depositarios distorsiona necesariamente la estructura productiva de una sociedad.

${ }^{3} \mathrm{El}$ modelo que desarrollo a continuación fue presentado en el IX Congreso de Economía Austriaca (1-2 de junio de 2016, Madrid, Instituto Juan de Mariana), mediante mi ponencia Por qué la reserva fraccionaria no es una institución del libre mercado. 
da al cabo de un mes (cuatro semanas), a la vez que el orfebre cobra sus emolumentos según la tarifa anunciada (Figura 1a).

\section{b) Pauta segunda: con reserva fraccionaria ${ }^{4}$}

En un momento dado, ante los gastos que se le van a presentar a causa de la boda de su hija (por ejemplo), el orfebre decide vender dos kilogramos de metal (de entre las cantidades depositadas en su taller, que por término medio vienen a ser cuatro encargos, con cuatro kilogramos), con la esperanza y la intención de que una bonanza o algún ingreso extraordinario le permitirá más adelante restituir el metal cuyo uso desvió. Dada la indistinguibilidad del metal procedente de distintas fuentes, el orfebre procede en adelante a utilizar, no el metal que cada depositante en su momento le entregó, sino el de la persona que viene a hacer su entrega dos semanas después (esto es, visto de manera conjunta o agregada, desplaza el uso del metal en dos lugares en la cadena de encargos [véase la Figura 1b]). En paralelo modifica su método de ejecución del trabajo de orfebrería, reduciendo el número de etapas que empleaba para transformar y dar forma final a cada pieza (además, al ser hombre avezado en el oficio, conseguirá que, conforme vaya poniendo en práctica tal abreviación, no se resienta en exceso la calidad del resultado).

Por otra parte, al ir pasando el tiempo, nunca ve llegado el momento de retornar el metal, con lo que dicha rutina pasará a convertirse en su manera habitual de trabajar. E incluso también le abandonará la sensación de malestar o incomodidad que le acom-

\footnotetext{
${ }^{4}$ Esta pauta está inspirada en un ejemplo que expuso el profesor Juan-Ramón Rallo en su conferencia de la jornada de clausura del II Congreso Economía y Libertad celebrado en la sede de Universidad Católica de Ávila Santa Teresa de Jesús el 8 de noviembre de 2014. En la fila para comprar entradas para el cine un individuo pasa sin pagar afirmando que el siguiente es el que paga «su» entrada, mientras que este, sorprendido, paga «una» entrada pero señala al siguiente como si fuera también ese siguiente quien pagaría «su» acceso, y así sucesivamente. Todo el mundo estaría contento hasta que llega una persona que ve que no hay nadie detrás de él en la cola. Propongo llamar a este tipo de pautas de comportamiento, cuando consigan perdurar, para-instituciones.
} 
pañaba, llegando a pensar que él había sido tonto por no haber seguido tal práctica desde mucho tiempo antes, creando un riesgo innecesario aumentado en caso de robo.

Transcurrido el enlace y su rumbosa celebración, vemos que en realidad «todo el mundo» está contento (aparte de los apuros que pasa nuestro orfebre por el ajuste del ritmo de trabajo en el taller): la boda de su hija se celebró sin estrecheces, el local de banquetes de lujo, que estaba a punto de cerrar por falta de clientes, ha cobrado nueva vida, sus proveedores han cobrado facturas pendientes, y alguno de ellos incluso ha ampliado el negocio y contratado a nuevo personal ante la mejora de las perspectivas. Los clientes del orfebre, por su parte, van recibiendo «una pieza» de metal trabajado conforme al boceto de su encargo y no se preocupan de más, ${ }^{5}$ y la confianza en nuestro orfebre parece no resquebrajarse.

Incluso podemos pensar que ante nuevos apuros (alguna factura aún pendiente) llegará a vender un nuevo kilogramo más de metal. Sin embargo, debido a la premura y la intranquilidad con que este hecho le obliga a trabajar, al poco tiempo volverá a recuperar, esto es, a comprar por su cuenta otro kilogramo de metal, para de esta manera volver a dejar el desfase de metal en el taller únicamente en dos kilogramos. Ello le permite no tener que trabajar con tanta urgencia, y no haber de extender su jornada laboral incluso al horario nocturno, como había sucedido durante este último periodo en los momentos de más apuro, previos a reintegrar el tercer kilogramo desviado (Fig. 1b).

En la Figura 1 mostramos gráficamente el desarrollo temporal de la actividad según se realice:

a) manteniendo la pauta tradicional de obligación de custodia;

b) no manteniéndola, y pasando a utilizar una pauta de reserva fraccionaria.

${ }^{5}$ A pesar de que se ven desprovistos del metal durante cuatro semanas, periodo de tiempo que viene a ser el doble del que realmente le cuesta al orfebre transformarlo conforme a su nueva forma de trabajar. 
FIGURA 1

ESQUEMA DE LOS PATRONES DE CONDUCTA QUE SIGUE EL ORFEBRE EN UNO Y OTRO CASO
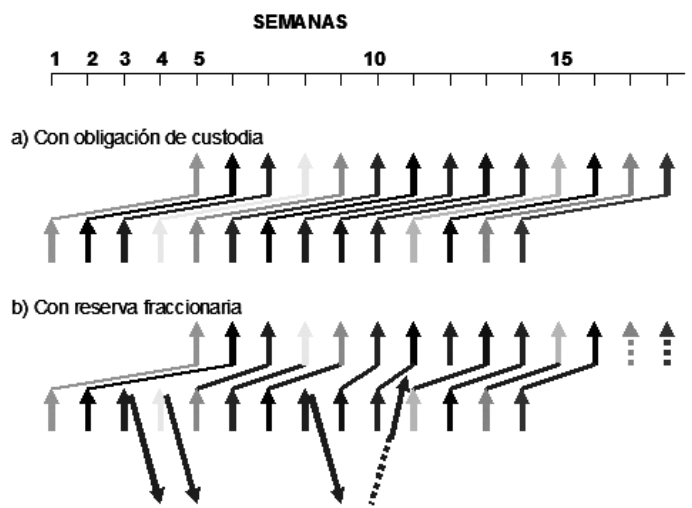

A partir de determinada fecha, en el pueblo de al lado se instala un chico joven que pretende abrirse camino también como orfebre. Aunque menos experimentado que él, la frecuencia de entrada de clientes en el taller de nuestro orfebre se resiente, por lo cual se siente como forzado ${ }^{6}$ por haber de pasar nuevos apuros para entregar sus trabajos en el plazo acordado. Se plantea incluso recuperar los dos kilos de metal y volver al ritmo anterior de trabajo, pero ahora las cosas no van tan bien y es incluso más difícil que antes recuperar la forma de trabajo tradicional (o como él la ve ahora: anticuada). Pero se le ocurre una idea alternativa, y gracias a sus relaciones personales, consigue que el alcalde del pueblo vecino le exija al nuevo orfebre garantías y documentación con el fin de proteger y asegurar a la población, especialmente a los más débiles y necesitados, de un posible incumplimiento por parte del orfebre novel, dado que no es persona asentada ni especialmente solvente. $Y$ ante tales dificultades añadidas, el joven competidor abandonará la población y la actividad.

\footnotetext{
${ }^{6}$ Obsérvese como la idea de aplicación de «fuerza» viene a ser vivida por nuestro orfebre, a partir del momento en que comienza a practicar la reserva fraccionaria, en sentido inverso al real.
} 
Tras un tiempo de calma, una tormenta de pedrisco sobre la cosecha principal de la comarca provoca que dejen de entrar nuevos clientes, y a la vez dos de los depositantes en espera le solicitan que, por favor, a ver si puede devolverles su metal, y que le pagarán la penalización acordada para tal eventualidad. Con buenas palabras primero, y con alguna amenaza velada después, consigue que desistan de su solicitud. Sin embargo, cuando van llegando los plazos de entrega, les solicita a sus clientes que, por favor, esperen un poco más de tiempo (y que «no se preocupen», que su metal está en buenas manos, y que en su encargo se está esmerando especialmente y con ello luego valdrá más). Como transcurridas las prórrogas rogadas, las excusas continúan, se extiende por el pueblo el rumor de que «algo pasa» con el orfebre (las buenas palabras, sus llamadas a la confianza, y los muchos años en el oficio que le avalan, no consiguen acallar el rumor). E incluso se ve obligado ${ }^{6}$ a advertir a uno de los depositantes que haga el favor de mantener la calma, si quiere recuperar el metal, pues es la buena marcha de todo el pueblo lo que está en juego, y sería un mal vecino si levantara dudas sobre su buen oficio. Sorpresivamente, el local de banquetes donde se celebró la boda de su hija ha cerrado, y ha dejado en la calle a sus trabajadores, y un montón de facturas de sus proveedores sin pagar. El desempleo en el pueblo crece a unos niveles nunca antes conocidos, arrastradas otras actividades también al cierre. Además, dos de entre los últimos depositantes (no necesariamente los dos últimos) no volverán a recuperar jamás «su» metal.

A partir de este modelo sencillo, y sus procesos, podemos estudiar los efectos que se dan según el orfebre practique una u otra pauta (nos centraremos en la segunda).

\section{Efectos (de la reserva fraccionaria) sobre los concretos contratantes-depositantes}

Al practicar el orfebre la segunda de las pautas (que ha acabado denominándose «reserva fraccionaria»), está disponiendo de la propiedad de cada concreto depositante sin su conocimiento. Está difuminando las señales o límites de lo que pertenece a cada quien, circunstancia que está en la base del orden espontáneo caracterís- 
tico evolutivo desarrollado por la humanidad (Shaffer 2009: boundaries of order). Cada concreto depositante se ve dañado, pues aumenta de manera muy significativa el riesgo de ver desaparecer «su» metal debido a una circunstancia no prevista (más allá de la posibilidad de robo por parte de un agente externo, o la eventual huida repentina e infundada del orfebre con el metal depositado - circunstancias poco probables en la versión tradicional de la actividad-). ${ }^{7}$ Por último, la apreciación del error o defecto de representación de los verdaderos costes o riesgos asociados al servicio contratado, lleva implícita que el cliente, de haberlos conocido, no lo hubiera contratado. ${ }^{8}$

Aunque son dos los concretos depositantes a los cuales se les habrá escamoteado su metal, la concreción del riesgo se verá retrasada en el tiempo, al entrar en juego la sucesión de plazos temporales para realizar las respectivas «devoluciones» (al desplazarse y utilizarse el metal de los nuevos depositantes para «devolver» los encargos de los depositantes anteriores). Tal concreción, vista como probabilidad de ver perdido efectiva y definitivamente «su» metal, se ve distribuida más o menos al azar entre todos los depositantes del taller como un juego de suma cero: lo que gana el orfebre, lo pierden sus depositantes en proporción a su número.

Así, en un primer momento, la probabilidad media estadística para cada depositante de perder su metal será de $2 / 4$ (tomados en conjunto de manera indiferenciada las cuatro personas que, en ese momento de introducción de la nueva pauta, tienen depositado su metal en el taller). Pero obsérvese que, en el caso de que vayan apareciendo nuevos entrantes-depositantes, y gracias a la posibilidad que se ha abierto de desplazar metal de unos a otros, la reciente pauta de reserva fraccionaria puede conseguir perdurar en el tiempo, lo que

\footnotetext{
${ }^{7}$ Este daño se hace más patente cuando se revelan ya desde el inicio los efectos de tal pauta: por ejemplo, por no conseguir el orfebre reducir o abreviar las fases de ejecución de los correspondientes trabajos (tras la boda). Entonces le vendrán y se acumularán reclamando su metal los cuatro clientes que tienen depositado en ese momento su metal, cuando solo existe metal para dos en el taller.

${ }^{8}$ Esta última frase (cambiando la palabra «producto» por servicio) ha sido tomada de la Sentencia del Tribunal Supremo español (sala primera de lo civil) $n^{\circ} 361$ de fecha 12 de febrero de 2016, que recoge la jurisprudencia reciente relativa a la problemática de la contratación bancaria.
} 
va ligado a que se diluye una parte del riesgo que sufrían los depositantes iniciales, en la misma medida en que se desplaza ese riesgo a los nuevos entrantes, pasando a ser la probabilidad media a medio plazo de 2/100 (suponiendo que fueran un centenar los clientes habituales del orfebre).

Aparte (y además) de este efecto directo sobre cada depositante, que tiene carácter expansivo (tiende a distribuirse más allá de cada concreto contratante, implicando a toda la comunidad de depositantes en ese concreto taller, presentes y futuros), un efecto adicional aparece y se ve distribuido, esta vez (no entre la comunidad de depositantes y acreedores del orfebre, sino) entre toda la sociedad o mercado. Es el efecto que ejerce la nueva capacidad de intercambio adicional (que ha surgido con la nueva práctica) sobre el proceso de formación del precio del concreto mercado en el que venga a intervenir el orfebre, bien sea como oferente, o como demandante (esto último será lo más frecuente; véase a continuación ambas posibilidades).

\section{Efectos más allá de los contratantes: efectos en el proceso de mercado derivados de la «disposición» por parte del orfebre de los $2 \mathrm{~kg}$ de metal depositados}

a) Cuando el orfebre actúa como oferente en el mercado de compra-venta del metal

Cuando el orfebre acuda como nuevo entrante oferente al mercado de compra-venta del metal, sus valoraciones subjetivas lo situarán probablemente en disposición de una mayor capacidad de intercambio que sus competidores a la hora de vender el metal. Consecuentemente, en el proceso de ofertas preliminares, contraofertas y pujas, previo a la determinación del precio de mercado (BöhmBawerk 1889: 203-210), ejercerá un papel que llevará a que se produzcan finalmente un mayor número de intercambios efectivos, con un menor precio de mercado, y también a desplazar a algunos de los oferentes que antes conseguían intercambiar (vender) su metal (véase Bueso [2016]: Tabla 2, excepto su subfigura 12 última aquí no aplicable). 
Obsérvese que la función que está ejerciendo aquí el orfebre sobre el proceso de mercado:

- Es la contraria $a^{9}$ de la correspondiente a la intención o voluntad del verdadero titular del metal, que ha decidido retirarlo de la circulación dándole forma de escultura,

- hace parecer a la generalidad de los agentes que existiría más metal del que realmente existe, $y$

- va contra los intereses del depositante, que verá como el referente que significa el precio de mercado del metal bajará (con lo que el metal de su propiedad en adelante tendrá una expectativa de menor capacidad de intercambio).

Pero, además de estas tres circunstancias, ¿qué ocurre si el metal está ejerciendo en esa sociedad la función de medio de cambio generalmente aceptado (dinero)?

\section{b) Cuando el orfebre actúa directamente como demandante}

Cuando la nueva capacidad de intercambio del orfebre actúe por el lado de la demanda llevará a que se produzcan un mayor número de intercambios efectivos también, pero esta vez el precio de mercado del bien por el que puje, será mayor, y a quien se desplazará será a algunos de los demandantes que antes, en las condiciones de libre mercado, conseguían intercambiar (comprar) y ahora no lo

\footnotetext{
${ }^{9}$ Aquí comienza a formarse el núcleo de desorden (y fuente del error sobre la percepción de las condiciones reales del mercado) cuyos efectos no son percibidos inicialmente, pero más tarde se manifestarán como lo que son (desajustes descoordinadores), por lo que muchos de ellos habrán de revertir. Obsérvese que el incremento de precios en este mercado de caballos no irá acompañado de la correspondiente disminución de precio en otros mercados, como ocurriría en el caso de un préstamo o de una donación (donde el actual depositante sí que habría realmente entregado y renunciado a su capacidad de disposición sobre el metal).

También observamos que existe un claro conflicto de intereses en la persona de un depositario que actúe a su vez en el mercado de compra-venta del concreto material que se ha depositado en su taller, salvo que diferencie muy bien la procedencia y el destino de cada concreta unidad de bien.
} 
lograrán. La siguiente Figura 2 ilustra un ejemplo concreto de este segundo caso.

FIGURA 2

EFECTO DE LA DISPOSICIÓN DE LOS DOS KG DE METAL DEPOSITADOS SOBRE EL PROCESO DE FORMACIÓN DEL PRECIO, CUANDO EL ORFEBRE ACTÚA POR EL LADO DE LA DEMANDA, SIGUIENDO EL CLÁSICO EJEMPLO DEL MERCADO DE COMPRA-VENTA DE CABALLOS DE BÖHM-BAWERK (1889: 203 [105])

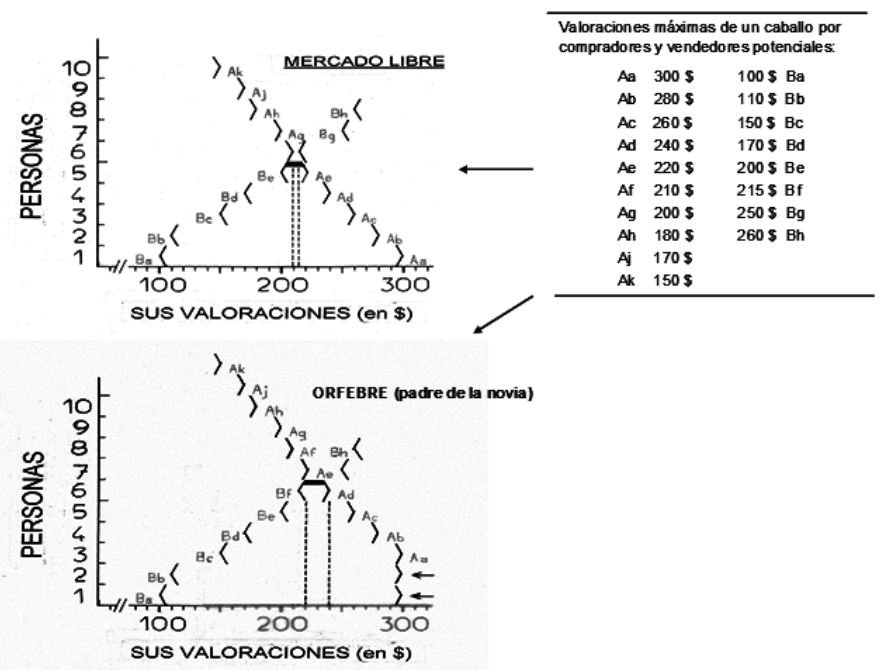

Representamos gráficamente la última fase previa a los efectivos intercambios, resultante del proceso de interacción. La Tabla representa las valoraciones tope de cada actor, según se indica en dicho ejemplo, por debajo o por encima de las cuales estaría dispuesto a intercambiar. Las respectivas gráficas muestran que:

a) En condiciones de libre mercado se vendrían a intercambiar 5 caballos (Ba-Be y Aa-Ae resultarán incluidos) a un precio de mercado que vendría a estar en el intervalo entre 210 y 215 \$. 
b) Cuando el orfebre que practica reserva fraccionaria puja por dos caballos, se vendrían a intercambiar 6 caballos (Ba-Bf y Aa$\mathrm{Ad}+2$ Orf) con un precio de mercado que resultará ahora más elevado, en el intervalo entre 220-240 \$ (precio más elevado que vendrán a pagar todos los compradores). El demandante Ae, además, quedará excluido (desplazado de su posición de comprador marginal), se volverá a casa sin un caballo.

En resumen, como consecuencia de la nueva práctica resultan beneficiados: el propio orfebre (que disfruta de un privilegio exorbitante prohibido a los demás), el vendedor de caballos Bf (que antes no conseguía vender su caballo), y también el resto de vendedores, al aumentar el precio de mercado. Resultan dañados: quienes vienen a comprar caballos, pues han tenido que pagar un precio mayor, y también especialmente el demandante Ae que ha quedado excluido.

En cuanto a los efectos generales, todos los usuarios del dinerometal de esa sociedad resultarán dañados, por una triple vía: por las distorsiones en la «estructura» de precios relativos, engañados también sobre cuáles son las tendencias generales del mercado, y a través de una disminución de la capacidad adquisitiva de su dinero. Dado que el dinero y los incrementos en su oferta vienen a constituir un juego de suma cero de carácter funcional (Mises 1912: 379; Bueso 2015: 160-161), el incremento en la capacidad adquisitiva del orfebre se vendrá a redistribuir, como una pérdida adquisitiva, de manera más o menos al azar, entre todos los usuarios de ese dinero en una serie de pasos sucesivos adicionales en el mercado. Esto es, los costes monetarios de esa nueva pauta de trabajo se socializarán, en paralelo a como se privatizan los beneficios especialmente en la persona del «orfebre». Estamos pues ante una pauta coactiva (aunque a primera vista pudiera parecer que solo existen interacciones voluntarias).

Téngase en cuenta que el «daño» cuantitativo y de exclusión inicialmente producido a concretas personas (esto es, los concretos demandantes que se ven desplazados de sus respectivos mercados, y quienes se ven obligados a pagar precios más elevados) no vendrá a ser compensado por los nuevos efectos que se producirían (en la dirección contraria) en el supuesto de que nuestro orfebre deci- 
diera más adelante volver a comprar dos kilogramos de metal para reintegrarlos a su taller, pues esos nuevos efectos recaerían ahora, en ese segundo momento posterior en el tiempo, sobre personas diferentes (con lo cual aquellas concretas personas iniciales dañadas seguirán resultando dañadas [Mises 1912: 160-162, 237-242]).

Siempre aparecen personas dañadas, muchos de ellos terceros, ${ }^{10}$ luego todo ello nos revela, también ahora por sus efectos sobre el proceso de mercado (la otra cara de lo que ocurre dentro del taller), que estamos ante una actuación que no respeta a cada persona, sus posesiones y su autonomía, que es lo que se exige en un verdadero mercado libre.

\section{Su contabilización}

En el oficio del orfebre tradicional, son dos cosas diferentes y se lleva o llevarían cada una por separado, la llevanza de un libro o registro de los depósitos conforme se van realizando, y devolviendo, en sus respectivas fechas, por un lado, lo cual es relativamente sencillo, y por otro lado, la llevanza de la contabilidad del propio negocio o actividad de orfebrería. A ningún orfebre tradicional se le hubiera ocurrido apuntar en el balance de su actividad el metal que le ha sido confiado en depósito (todos los agentes tenían claro que nadie estaba donando ni prestando nada a nadie). ${ }^{11}$

Nuestro orfebre "poco escrupuloso", sin embargo, como modo de disimular su poco ortodoxa conducta, pasaría a incorporar lo depositado por sus clientes en su propio balance, como un activo adicional de su negocio, ${ }^{12}$ por un lado, y como un crédito que debe

${ }^{10}$ Lo que nos revela que estamos ante un juego con resta (Bueso 2015: 151, 157, 161163) institucionalizado, con efectos disruptivos y descoordinadores. En concreto, la reserva fraccionaria se comporta a modo de vórtice o máquina bi-funcional, que por un lado extrae y concentra bienes hacia los detentadores de esa función emergida extraña al libre mercado (en este caso, nuestro orfebre sui géneris, a la vez que otros agentes también resultan beneficiados secundariamente por su relación con el mismo, como el vendedor Bf del ejemplo), a costa de los demás, la generalidad de las personas.

${ }^{11}$ Por eso en el derecho romano, y en otras tradiciones jurídicas, emergieron como dos instituciones separadas, que no tenían nada que ver la una con la otra, el depósito por un lado, y el préstamo por otra.

${ }^{12}$ Nótese que de esta manera un mismo bien pasa a aparecer como Activo en los balances contables de dos personas diferentes; esto es, a duplicarse. Fue Böhm-Bawerk 
devolver en un futuro, por el otro. Con ello, el beneficio empresarial estimado de su actividad vendrá a depender en gran medida de cuál sea el porcentaje del metal de sus clientes que «decide elegir» que ha pasado a ser de su disponibilidad (esto es, de su propiedad, esas 2/4 o 3/4 partes de nuestro ejemplo; así, los hinchados beneficios estimados se convertirán, además, en un acordeón, según varíe ese porcentaje elegido). Nótese que ahora el principal negocio deja de ser la orfebrería, y pasa a serlo esa actividad o capacidad de duplicar o apropiarse de la disponibilidad del metal de sus clientes, como un privilegio que no pueden realizar las demás personas (pues además de ir contra la ley material, no se encuentran en situación de poder acometerlo, por no ejercer la función de depositarios de los bienes de los demás).

\section{Otro efecto transcendente: los agentes implicados se ven fuertemente inducidos o impulsados a practicar coacción sobre terceros}

Como hemos visto en el modelo, la sostenibilidad del nuevo esquema practicado por el orfebre ocasiona una tremenda dependencia del ritmo de entrada de nuevos clientes (a diferencia de la pauta tradicional de trabajo, que se amolda a las diferentes circunstancias). Ello lleva necesariamente a que se generen, en respuesta a las oscilaciones naturales del ritmo de entrada de nuevos clientes, dos urgencias o necesidades imperiosas por las que «el orfebre» (que se juega en ello su propia supervivencia, y en las que las personas que

en Whether legal rights and relationships are economic goods (Böhm-Bawerk 1881: 134-137) quien demostró que una promesa no es un bien económico (de hecho no es un bien, no es un bien diferente; cuestión que se sitúa en el centro de los problemas debatidos), y apuntó al cúmulo de errores conceptuales relacionados con esta consideración duplicada de unos mismos bienes económicos. A raíz de dicho estudio se propone (Bueso 2015: 149, 168) que la integración del principio de propiedad requiere que se defina con claridad y que cada parte sea consciente de lo que de verdad se está intercambiando por cada parte en cada concreto contrato, que podrá ser:

a) un bien presente se intercambia por otro bien presente

b) un bien presente se intercambia por una promesa (crédito mercancía)

c) lo que se intercambian son promesas. 
se han visto implicadas en el esquema «empujarán» también en esa misma dirección) se ve fuertemente inducido a utilizar medios coactivos frente a terceros en la dirección de:

a) cerrar o restringir coactivamente la competencia en su propia actividad, en tanto que la misma abriría nuevas alternativas u opciones a sus eventuales clientes (téngase en cuenta que la posibilidad de conseguir los mismos resultados por medios no coactivos es muy remota, ya que el sector, por los elevados beneficios que esa nueva práctica o función genera, se convierte en especialmente atractivo)

b) conseguir «nuevos entrantes» en el esquema, lo que aboca a utilizar medios coactivos también para integrar nuevos bienes de terceras personas (para poder así utilizarlos para satisfacer los contratos previos incumplidos), bien sean nuevos depósitos, $\mathrm{u}$ otros.

Esta escalada coactiva resulta ser típica de las intervenciones coactivas en el mercado (Bueso 2016). Luego proponemos que la reserva fraccionaria es una pauta o para-institución coactiva, no solo desde el momento en que se produzcan estas reacciones inducidas (tras revelarse los efectos, la insostenibilidad del esquema), sino «desde el inicio», cuando se comenzó a practicar la misma, cuando el orfebre se apropió del metal de sus depositantes.

\section{Conclusiones del modelo de depósito}

Este sencillo modelo de depósito nos ayuda a visualizar los procesos que se desencadenan según el depositario actúa siguiendo una $\mathrm{u}$ otra pauta o regla de conducta. A partir de los efectos descubiertos (tanto entre contratantes, como por la externalización de costes que de varias maneras se produce), llegamos a la conclusión que la práctica de la reserva fraccionaria no respeta lo que se exige en un verdadero mercado libre. $Y$ es que se externalizan costes por parte del orfebre, al concreto depositante cuyo metal se ha visto implicado en su «olvido» inicial de la pauta tradicional, en un primer mo- 
mento, y a continuación hacia el conjunto de depositantes de ese concreto periodo. Y más adelante, en un tercer momento, en sucesivas etapas, desde los depositantes de un determinado periodo hacia los del siguiente que le sucede en el tiempo. Y paralelamente, a través del proceso de mercado, a toda la sociedad.

Esta recurrente externalización de costes genera una extremada dependencia del esquema hacia la entrada de nuevos depositantes (requiere una constancia casi absoluta en el ritmo de entrada, o bien un incremento continuado, de nuevos clientes), lo que hace a la reserva fraccionaria una política no sostenible en el tiempo a medio o largo plazo. El incremento de beneficios extraordinarios que tal práctica produce atraerá a dicho campo a nuevos orfebres competidores, lo que conduce a una disminución en la entrada de nuevos depósitos en los talleres de los orfebres instalados, lo que provocará de manera inexorable la quiebra de dicho esquema... salvo que se venga a aplicar nueva coacción, por ejemplo cerrando coactivamente la entrada a nuevos orfebres, o incluso disminuyendo (o fusionando) el número de los ya existentes: monopolio coactivo (según fue redefinido por Rothbard [1962: 654-658]). ${ }^{13}$

Lo descubierto en nuestro modelo es aplicable igualmente a la emisión por parte del depositario de pseudo-certificados (o promesas extranumerarias), más allá, o aparte, de la cantidad de material que realmente se ha depositado en su taller, en la medida en que los mismos circulen como si fueran «bienes», debido a la especial credibilidad que tienen por provenir de un depositario. Y téngase en cuenta además que, cuando el metal está ejerciendo la función de medio de cambio, desaparece incluso ese límite material que supone la necesidad de abreviar las fases para transformar el metal (en el oficio de orfebrería), pues tales medios actúan como sustitutos monetarios perfectos y ejercen su arrogada función monetaria ${ }^{14}$ sin

${ }^{13}$ También se está excluyendo a los aspirantes a ejercer de orfebres estrictos (que no tendrían intención de hacer uso de esa nueva práctica de reserva fraccionaria), a los que se les cierra igualmente la puerta. Pero téngase en cuenta que existe daño a terceros no solamente desde que se levantan esas barreras de entrada coactivas (tras revelarse los efectos, la insostenibilidad del esquema), sino desde el inicio (aunque no sean conscientes de ello quienes resultan afectados).

${ }^{14}$ Obsérvese que la típica neutralidad de las instituciones espontáneas de Menger (1871: 257-261) en relación a todos y cada uno de los agentes, desaparece en la institu- 
necesidad de venir a reclamarse en ningún momento su redención (Mises 1912: 300-304, 355-359). Se abre así la posibilidad de expandir los medios de pago en el corto plazo «sin límite» ninguno (prolongando sus efectos descoordinadores).

III

PROPUESTA DE UN MODELO SENCILLO

TAMBIÉN PARA EL CRÉDITO, QUE PERMITA

PERCIBIR LO QUE OCURRE CUANDO SE PRACTICA CON DESCALCE DE PLAZOS

Supongamos ahora para el caso del crédito, ${ }^{15}$ que en su isla Viernes tiene una cantidad determinada de moras ahorradas, y conviene con Robinson prestárselas por un plazo de diez días, quien a su vez tiene un proyecto de inversión (pongamos, siguiendo el ejemplo clásico, que el mismo consiste en la construcción de una vara de madera que considera que le permitirá alcanzar y recoger moras con mayor eficiencia en el futuro) cuyo proceso de fabricación ha estimado que se vendrá a prolongar durante veinte dias. Se produce un descalce de plazos entre el crédito obtenido (diez dias) y el proyecto que Crusoe va a emprender (veinte días).

Cabe suponer que la perspicacia empresarial de Robinson habrá aventurado que tras esos diez días o bien Viernes o bien algún otro nuevo entrante habrá ahorrado (y además tendrá la voluntad de prestárselas) una nueva cantidad semejante de moras, con lo cual el nuevo préstamo negociable le permitirá subsistir hasta poder finalizar su proyecto. Pero no existe certidumbre de que tal hecho ocurrirá, pues dependerá de circunstancias y voluntades ajenas al propio Crusoe. Luego existe el riesgo de que transcurridos los diez días se le agoten las provisiones con su vara sin termi-

ción dinero a partir del preciso momento en que las promesas de un determinado agente pasan a arrogarse tal función.

${ }^{15}$ Este modelo es un desarrollo del apuntado por el profesor Philipp Bagus en el interesante debate sobre esta cuestión que realizó con Juan Ramón Rallo en la conferencia de European Students for Liberty que se celebró en Madrid el 25 de octubre de 2014 (minutos 35-40; https://www.youtube.com/watch?v=YshZJMxIZe8, accesible en YouTube). Véase también Bagus et al (2010 y 2016). 
nar, abocándole a tener que abandonar su proyecto frustrado, debiendo retornar a su pauta de recogida diaria de moras para poder subsistir en el día a día (aparte de dejar incumplida su promesa de devolverle las moras a Viernes).

$\mathrm{Al}$ igual que en el crédito que no descalza plazos, en tanto Crusoe no ocultara su situación, no vemos nada contrario al libre mercado (entendido como respeto a cada persona, sus bienes y su autonomía) en ninguna de las opciones presentadas. Sí que sería contrario al libre mercado que transcurridos los diez días Robinson se tomara para sí mismo «la libertad» (entre comillas) de agredir a Viernes y quitarle, o «tomar» prestadas, las moras de las que este pudiera disponer, por ejemplo.

Es cierto que al aumentar el crédito se favorece el emprendimiento de procesos de producción a más largo plazo, y que este auge $u$ optimismo puede devenir frustrado, especialmente cuando se da el descalce de plazos. Pero ello entra dentro de la incertidumbre implícita en cualquier actividad empresarial. Si se integra el principio de propiedad en las respectivas actividades e intercambios (en este concreto caso de crédito, lo que se está entregando a cambio de disponer de los bienes reales - moras- de Viernes es una promesa por parte de (rusoe), los daños derivados del incumplimiento de la promesa por parte del prestatario, quedan estrictamente entre las partes contratantes. A nadie se le puede obligar a entregar lo que no tiene. A nadie se le puede obligar a prestar sus bienes, en un mercado libre. Esto es, por ninguna de las dos partes se está aplicando violencia o coacción a terceros no contratantes ni a nadie. La frustración de las expectativas ${ }^{16}$ es una eventualidad posible (que no deja de estar) implícita en el libre mercado.

\footnotetext{
${ }^{16}$ Cuando los autores de la Escuela Austriaca hablan de expansión «artificial», ese término no se refiere a la que va seguida de esta frustración de expectativas «natural» cuando algunos agentes o un concreto grupo yerran en sus expectativas, pues en un mercado libre las oportunidades de beneficio hacen que los errores no estén correlacionados. Lo hacen en referencia a la frustración general derivada de un error colectivo y sistemático («todos» en la misma dirección), característico de una intervención coactiva interfiriendo en la economía (Bagus et al 2016). Dicho error se desvela pasado un tiempo después de que algún concreto agente haya estado actuando en el mercado sistemáticamente en sustitución de los agentes realmente titulares de unos bienes que luego resulta que no solo no están allí, ni son de su titularidad (y que
} 
Por otro lado, no existe ningún motivo especial por el que debieran acumularse en un momento temporal determinado los vencimientos de ninguna eventual serie de estos préstamos con sus plazos descalzados. Luego, aunque una parte de sus efectos (el probable incumplimiento de su obligación o promesa por parte de quien recibe las moras por uno u otro título) pudiera parecer similar, la naturaleza de ambos procesos (descalce de plazos, y reserva fraccionaria) es radicalmente distinta.

Veamos ahora en un contexto similar qué sucede con la reserva fraccionaria. Imaginemos que alguno de los dos se dedicara a guardar las moras de ambos (en tanto deciden consumirlas). El registro de las moras que cada uno entrega sería una práctica normal. La «circulación» de los registros también podría serlo (sería una práctica no inflacionaria, en la medida en que los correspondientes registros se correspondieran con la realidad; esto es, en tanto sean realmente títulos de propiedad o certificados de depósito). Pero no ocurrirá lo mismo a partir del preciso momento en que el depositario emita falsos «certificados» de depósito más allá de las moras que se le hubieren entregado (por mucho que el mismo quiera considerarlas «promesas»). Su emisión induce a sus conciudadanos a creer o figurarse que existen más moras disponibles de las realmente existentes, y en consecuencia a trabajar, o tomarse unas vacaciones, o emprender proyectos de inversión de acuerdo con esa información. Proyectos que devendrán frustrados cuando se revele la realidad y haya que echar mano a las (supuestas) moras para alimentarse (porque con «promesas» uno no puede hacerlo). No estamos hablando de meras expectativas frustradas: no le hará mucha gracia la situación a aquel que entregó moras y ahora le dicen que no están (porque se las ha comido el otro, el depositario). ${ }^{17}$

$Y$ es que no es lo mismo ser el propietario de un bien que el acreedor de una promesa (por muy garantizada que la misma se presente, o muy solvente parezca ser el promitente). Lo que hay en

\footnotetext{
lo que ese agente en realidad ofrecía eran solo "promesas»), sino que no existen en ningún lugar (véase el apartado II-3a y la anterior nota 12).

${ }_{17}$ Precisamente lo que caracteriza a la situación de hecho que está detrás de la institución del depósito viene a ser que no se transfiere la disponibilidad o propiedad de la cosa entregada «en depósito» (Huerta de Soto 1998: 23, 110-112, 126-128).
} 
la base de una crisis derivada de descalces de plazos serían meros incumplimientos de promesas, que quedan entre las partes porque es una eventualidad que los mismos han asumido. Mientras que detrás de la reserva fraccionaria lo que existe son «propietarios»o titulares de bienes que vienen a darse cuenta «con retraso» de que «sus» bienes han desaparecido, les han sido escamoteados, debido a la (supuesta) duplicación de bienes, o efectiva «des-diferenciación» de qué es lo que pertenece a cada quien, denunciada o señalada por Böhm-Bawerk (véase la nota 12).

Luego podemos llegar a la conclusión de que el descalce de plazos (entre particulares) sí es una práctica del libre mercado, a diferencia de la reserva fraccionaria en el depósito, si bien no es probable que alcance una gran extensión práctica.

\section{IV \\ CÓMO LLEGA EL DESCALCE DE PLAZOS \\ A SER UNA PRÁCTICA HABITUAL}

Parece lógico pensar que el descalce de plazos únicamente podría llegar a ser una práctica habitual en situaciones donde la curva de tipos de interés mostrara un incremento muy marcado en relación a un mayor plazo del préstamo. En otro caso apenas tiene sentido. Así, en nuestro modelo de Viernes y Crusoe no parece razonable que el plazo acordado sea de diez días, sabiendo Crusoe que no terminará la vara en menos de veinte, y viendo Viernes que Crusoe no estará en disposición de «devolverlas» (esto es, entregar otras tantas de la misma calidad que las que recibió en préstamo - tantumdem-) de ninguna de las maneras en tan solo diez días. Y si no llegan a un acuerdo para prestarlas con ese plazo más largo, probablemente no se producirá ningún préstamo. ¿Cómo resulta entonces que tal práctica tiene tan gran prevalencia en la actualidad?

En nuestros días los Bancos Centrales intervienen presionando a la baja los tipos de interés a corto plazo (pues son los únicos o los más fáciles de modificar a la baja, pues a largo plazo hay otros factores que no pueden controlar: riesgo de inflación, riesgo de liquidez, riesgo de impago...). Resultado de dicha intervención se produce un diferencial enorme entre los tipos a corto y a largo plazo. 
Y así les ponen en bandeja a las Entidades de Crédito (cuyo número está limitado en tanto que monopolio, regalía gubernamental o privilegio, para poder acceder a dichas «facilidades») un negocio muy lucrativo (el negocio "de su vida»): endeudarse a corto y financiar a largo plazo, refinanciando constantemente sus posiciones. ${ }^{18}$

Solo en circunstancias como las descritas una práctica como el descalce de plazos podrá llegar a aparecer en forma de fenómeno masivo, en tanto que elemento accesorio integrado dentro de una cadena de privilegios coactivos, ${ }^{19}$ que habrán aparecido como forma de favorecer y colaborar con dichos monopolios.

\section{$\mathrm{V}$ \\ CONCLUSIONES}

A partir de los modelos correspondientes, hemos mostrado como la práctica del descalce de plazos en el crédito, aunque se aventura problemática, en sí misma no tiene efectos sistémicos negativos: los efectos quedan entre los concretos contratantes, no se externalizan costes a nadie (o, expresado en otros términos: nadie ha iniciado la violencia o la coacción contra ninguna persona, sus posesiones o su autonomía). Y lo mismo ocurre cuando el orfebre sigue la pauta tradicional en el depósito, no se difuminan las señales o los límites de lo que le pertenece a cada quien, y cada persona obtiene lo que

${ }^{18}$ Véase la conferencia de Miguel-Ángel Alonso el 3 de marzo de 2015 en la $5^{\text {a }}$ sesión del curso Repensar la Economía; más allá del homo-economicus en la Universidad Complutense de Madrid, especialmente los minutos 63 a 66 (https://www.youtube. com/watch?v=NURzCQ1rUg8, accesible en YouTube). Y Alonso et al (2011) para una visión integral de las diferentes teorías sobre el ciclo económico.

Por su parte, Ricardo Dias de Sousa en su ponencia Descalce de plazos y reserva fraccionaria dentro de la Teoría Austriaca presentada el 27 de mayo de 2015 en el VIII Congreso de Economía Autriaca organizado por el Instituto Juan de Mariana (https:// www.youtube.com/watch?v=pxhE1Ot1RsY, accesible en YouTube), en los minutos 13 a 17 explicó por qué Mises se centró solo en el fenómeno «de base», la reserva fraccionaria (olvidándose por un lado del banco central y por otro de los bancos de inversión, que eran los que mayormente descalzaban plazos en aquellas fechas).

${ }_{19}$ Véase el comentario de Philipp Bagus en el minuto 36-37 del debate señalado en la anterior nota 15, indicando que en el descalce de plazos no existe problema de descoordinación interpersonal, sino que los problemas vienen a partir del intervencionismo estatal y las garantías coactivas; y también Bagus (2010). 
acuerda voluntariamente con sus contrapartes, salvo incumplimientos puntuales. No ocurre lo mismo, sin embargo, cuando el orfebre practica reserva fraccionaria, donde desde el inicio se están desalineando beneficios y costes y externalizando costes a terceras personas.

A veces los partidarios de la reserva fraccionaria arguyen que, en realidad, no estaríamos ante un depósito sino ante un «contrato tácito» de préstamo «a la vista» (sin plazo). ${ }^{20}$ Quienes esto defienden están admitiendo, entre otras cosas, que lo que afecta y acarrea costes a tres o más personas sea decidido solo por dos de ellas (que realizarían «su contrato» a costa o en perjuicio de esos terceros a quienes ni siquiera les dan voz). Y es que aquí, cuando el depositario practica reserva fraccionaria, se están externalizando costes a tres niveles:

a) desde el depositario a cada concreto depositante, y desde estos hacia la comunidad de depositantes, presentes y futuros

b) a los eventuales aspirantes a orfebres, a los que difícilmente se les permitirá trabajar

c) a la ciudadanía en general, a través del proceso de formación de precios.

También apuntamos en este trabajo hacia otros daños y distorsiones que se producen a nivel microeconómico, de manera complementaria a los ya señalados por Huerta de Soto (1998: 535-542). ${ }^{21}$ Por un lado, mediante la Figura $2 \mathrm{~b}$ he intentado mostrar que en el específico proceso de formación de precios del mercado en que participe el orfebre, también son concretas las personas, terceros,

\footnotetext{
${ }^{20}$ Véase, por ejemplo, «La banca con reserva fraccionaria», por Francisco Capella, en diversas páginas web.

${ }^{21}$ Quien con la serie de gráficos VIII-1 a 4 demuestra que la estructura productiva de la sociedad (por sectores, de menos a más alejados del consumo final, dentro del triángulo hayekiano) se ve necesariamente distorsionada por la aparición de medios fiduciarios en el crédito, alejándose de los deseos y necesidades de la sociedad, implicando dolorosos reajustes. También muestra Huerta de Soto (1998: 515) que incluso en el caso de que dichos medios fiduciarios fueran exclusivamente destinados a la compra (directa) de bienes de consumo, se producirá una descoordinación intratemporal, al tender a generar una estructura productiva que a nivel horizontal no coincidirá con las que desean mantener a medio y largo plazo los consumidores.
} 
quienes sufren un daño por la disposición por su parte del metal depositado (o por la creación, y uso, de medios fiduciarios); y que dicho daño, no revierte. Y por otro lado, hemos encontrado el origen de las reacciones desequilibradoras (que más adelante se revelarán insostenibles e incompatibles con las verdaderas valoraciones de las personas) en los primeros pasos en que actúa el orfebre con esa capacidad de intercambio «nueva» descubierta (a la que no ha renunciado su titular), donde existe un claro conflicto de intereses, junto a un redireccionamiento en sentido opuesto al que seguiría el mecanismo auto-equilibrador de los precios, según las cantidades realmente disponibles y las preferencias demostradas por los titulares de los concretos bienes (de existir). Por otra parte, tampoco a Viernes le hará mucha gracia cuando vaya a recuperar sus moras, las que depositó, y las mismas no estén y no tenga qué comer (porque se las habrá comido Robinson). O cuando le digan que él no puede ejercer de orfebre (con esa misma pauta). ${ }^{22}$

Por todo lo expuesto, la principal conclusión o idea-fuerza de este estudio sobre la reserva fraccionaria en el depósito (salvo opinión mejor fundada), viene a ser que la extrema dependencia de la entrada de nuevos depositantes, unido al efecto llamada del incremento en beneficios extraordinarios o «artificiales» que dicha práctica genera (que en un mercado libre comportará la «entrada» de nuevos orfebres, lo cual ha de provocar necesariamente que decaiga el ritmo de entradas de nuevos depósitos en los talleres de los depositarios ya instalados, ritmo que es vital para mantener la base metálica del taller y evitar la alternativa de la quiebra), aboca a acabar generando un monopolio con barreras de entrada coactivas. Y que esta situación recurrirá, y con ella la «necesidad» de aplicar nuevas formas de coacción.

Luego la práctica de reserva fraccionaria constituye un núcleo coactivo, con efectos difuminadores de los límites del principio de propiedad, que a su vez retrasa en el tiempo la percepción de la correspondiente externalización de costes (origen de su manifesta-

${ }^{22}$ Lo que revela que estamos ante un privilegio. Obsérvese que si una determinada sociedad «legisla» haciendo legal (formalmente) dicha práctica, los efectos relatados se seguirán produciendo igualmente. Y lo mismo ocurrirá cuando sea el sistema judical el que no actúe eficazmente cortando tal tipo de prácticas. 
ción temporal como un auge económico artificial inicial seguido por una posterior recesión, y causa última de tales procesos cíclicos cuando son estudiados desde sus elementos más simples [Bueso 2015: 167-171]). Es una política no sostenible en el tiempo, y supone un «atractor» para la aplicación de nueva coacción, lo que ocurrirá especialmente cuando se vengan a manifestar esos costes inicialmente no percibidos. En aras a su continuidad, se introducirán entonces barreras de entrada, junto con fusiones obligadas o inducidas para los orfebres ya instalados, buscando una disminución del número de agentes a los que se les permite tal práctica. También «llamará» a la aplicación de (tendiendo ella misma a generar, o a alinearse con) otras reglas o para-instituciones también coactivas. ${ }^{23}$

Por otra parte, el crédito con descalce de plazos, aunque en sí mismo no es una práctica coactiva (no deja de tener naturaleza coordinadora interpersonal en tanto se practique integrando el principio de propiedad, según hemos visto en el modelo de la isla), cuando aparezca acompañando a otras prácticas que sí que son coactivas (como la reserva fraccionaria, los monopolios o el dinero-fiat), coadyuvará a «retrasar» en el tiempo la percepción del daño o el desplazamiento de costes asociado a tales prácticas. ${ }^{24}$

${ }^{23}$ Así, en palabras de Guido Hülsmann, nuestro orfebre, tras la boda de su hija, se ha convertido en un political entrepreneur [which] «tests the market to discover how far he can go in violating property rights without encountering resistance. Each uncovered ticket that he can bring into circulation, each new institution that fosters the continuing circulation of uncovered tickets, is a further political discovery» (Hülsmann 2003: 419, y su nota 14). Estos descubrimientos políticos integrados en esa escalada coactiva (bancos centrales prestamistas de útima instancia primero, introducción del dinerofiat después, y luego ese mismo banco central gestionando la introducción en el día a día de la nueva base monetaria mediante préstamos a cortoplazo al grupo de agentes privilegiados) serán las causas cuya externalización de costes y efectos dañosos y descoordinadores, enmascarada y retrasada en el tiempo su percepción (vía descalce de plazos — ver a continuación-, junto a otras), se manifestarán acumulados de manera retardada (Baeriswyl 2015; Davidson 2014 y 2015).

${ }^{24}$ El crédito circulatorio vendría a estar constituido por un mero intercambio de promesas. Sin embargo, el receptor, llegado el día, deberá «devolver» (y pagar intereses en forma de) verdadero metal. Y si además le toca «devolverlo» ya entrado el periodo de recesión, con su deflación de precios asociada a la desaparición de gran parte de las anotaciones pareadas en los balances de tales agentes privilegiados (que estaban ejerciendo la función de dinero «en sentido amplio» e inflando los precios [Carroll 1859; Mises 1912]), entonces se ve con mayor crudeza los efectos de este esquema monopolístico, pues el daño se concentra parcialmente en su persona (en vez de 
Así, posibilitando ese retraso en la percepción del daño-costes, consigue alargar o prolongar en el tiempo el auge «artificial» (y con ello también aumenta la descoordinación entre los agentes).

\section{REFERENCIAS BIBLIOGRÁFICAS}

Alonso, M.A., Bagus, P., y Rallo, J.R. (2011): «Teorías del ciclo económico: principales contribuciones y análisis a la luz de las aportaciones de la escuela austriaca de economía», Información Comercial Española, ICE: Revista de economía, vol. 858, pp. 71-87.

BAERISWYL, R. (2015): «Intertemporal discoordination in the 100 percent reserve banking system», Procesos de Mercado vol. XII, $\mathrm{n}^{\circ} 2$, pp. 43-80.

BAGUS, P. (2010): «Austrian business cycle theory: Are 100 percent reserves sufficient to prevent a business cycle?», Libertarian $\mathrm{Pa}$ pers, vol. 2, no 2, pp. 1-18.

BAGus, P. y HowDEn, D. (2010): «The term structure of savings, the yield curve, and maturity mismatching», The Quaterly Journal of Austrian Economics vol. 13, n 3, pp. 64-85.

- y HueRTA DE Soto, J. (2016): «Entrepreneurial error does not equal market failure», Journal of Business Ethics DOI: 10.1007/ s10551-016-3123-9

BARNETT, W., y Block, W. (2009): «Time deposits, dimensions, and fraud», Journal of Business Ethics vol. 88, $\mathrm{n}^{\circ}$ 4, pp. 711-716.

BÖHM-BAWERK, E. (1889): The Positive Theory of Capital (libro IV «Price», capítulo IV: «Two-side competition»), Auburn AL, Ludwig von Mises Institute (2007), pp. 203-213; y en castellano: Lecturas de Economía Política vol. I, Unión Editorial, pp. 99-142.

- (1881): "Whether legal rights and relationships are economic goods», en Shorter classics of Eugen von Böhm-Bawerk, vol.1, 1962, Libertarian Press Inc., pp. 25-138.

Bueso, J. (2015): «Teoría del intercambio: propuesta de una nueva teoría de los cambios interpersonales basada en tres elementos más simples», Procesos de Mercado, vol. XII, no 1, pp. 143-176.

únicamente diluirse y extenderse hacia terceros, como ocurre habitual y cotidianamente durante la fase expansiva). 
- (2016): «Intervención coactiva en el mercado: procesos, modalidades y efectos», Procesos de Mercado, vol. XIII, n 1, pp. 165-197.

Carroll, C.H. (1859): «Bankrupcy in the Currency», Hunts's Merchant Magazine and Commercial Review, vol. XL, pp 673-688, recogido en Organization of Debt into Currency and Other Papers, William Volker Fund/ Van Nostrand Ltd. (1972), pp.151-175.

DAVIDSON, L. (2014): «The economic consequences of loan maturity mismatching in the unhampered economy», The Quarterly Journal of Austrian Economics vol. 17, n 1, pp. 67-91.

- (2015): «Ethical differences between loan maturity mismatching and fractional reserve banking: A natural law approach», Journal of Business Ethics vol. 131, n 1, pp. 9-18.

HuerTa De Soto, J. (1998): Dinero, Crédito Bancario y Ciclos Económicos, Madrid, Unión Editorial (2006, $3^{\mathrm{a}}$ ed.).

HÜlSMAN, J.G. (2003): «Has fractional-reserve banking really passed the market test», The Independent Review, vol. VII, no 3, pp. 399-342.

Menger, C. (1871): Principles of Economics, Auburn AL, Ludwig von Mises Institute (2007).

Mises, L. (1912): Thery of Money and Credit, Liberty Fund.

Rothbard, M. (1962 y 1970): Man, Economy, and State, edición conjunta con Power and Market, Auburn AL, Ludwig von Mises Institute (2009).

SelgiN, G., y White, L. (1996): «In defence of fiduciary media -or, we are not devo(lutionists), we are misesians!», Review of Austrian Economics vol. 9, no 2, pp. 83-107.

SHAFFER, B. (2009): Boundaries of Order: private property as a social order, Auburn AL, Ludwig von Mises Institute. 
